\title{
Determine curcumin concentration in organ rats and in ovaries at ovarian cancer model rats using ultra performance liquid chromatography-mass spectrometry (MS)/MS
}

\author{
Ni Made Dwi Sandhiutami1,2, \\ Wawaimuli Arozal ${ }^{3 *}$, \\ Melva Louisa ${ }^{3}$, \\ Deni Rahmat ${ }^{2}$ \\ 1 Doctoral Program in Biomedical Sciences, \\ Faculty of Medicine, Universitas Indonesia, \\ Jakarta, Indonesia \\ 2 Faculty of Pharmacy, University of \\ Pancasila, Jakarta, Indonesia \\ 3 Department of Pharmacology and \\ Therapeutics, Faculty of Medicine, \\ Universitas Indonesia, Jakarta, Indonesia
}

*Corresponding author:

Wawaimuli Arozal

wawaimuli.arozal@ui.ac.id

Keywords:

curcumin, curcumin nanoparticles, UPLC MS/MS, rats organ,

ovarian cancer rats

\begin{abstract}
Curcumin has several pharmacological effects including anti-inflammatory, reduce kidney damage, hepatoprotector, and inhibiting tumor growth in ovarian cancer. The use of curcumin is limited because it has low bioavailability and low capacity to reach target organs. This limitation is overcome by making it in the form of nanoparticles. This study aim to determine curcumin levels on some organ in healthy rat groups and on ovaries at ovarian cancer models rat that given curcumin and curcumin nanoparticles. Measurement of curcumin levels using UPLCMS/MS. Determination of curcumin level in the organ was carried out in 2 treatment groups, group that received curcumin and group that received curcumin nanoparticles orally with a single dose of $100 \mathrm{mg} / \mathrm{kg}$ Body Weight (BW). At 180 minutes, rats were decapitated for liver, kidney and ovaries. The ovarian cancer rats were also divided into 2 groups and given curcumin and curcumin nanoparticles with repeated doses of 100 $\mathrm{mg} / \mathrm{kgBW} /$ day and after 30 days, ovarian cancer rats were decapitated for the ovaries. In the group that received curcumin, the concentration of curcumin in the liver, kidney and ovaries were less than the detection limit, whereas in the group that received curcumin nanoparticles, the levels of curcumin are $1,866.6 \pm 22.60 \mathrm{ng} / \mathrm{g}$ in liver, $114.87 \pm 13.36 \mathrm{ng} / \mathrm{g}$ in kidney and $136.864 \pm 11.15 \mathrm{ng} / \mathrm{g}$ in ovaries. In ovarian cancer rats, levels of curcumin in the group receiving curcumin is $2.29 \pm 1.15 \mathrm{ng} / \mathrm{g}$ and $17.76 \pm 4.85 \mathrm{ng} / \mathrm{g}$ in the group receiving curcumin nanoparticles. Curcumin nanoparticles can increase the distribution of curcumin in liver, kidney, ovaries in healthy rats and in ovaries at ovarian cancer model rats.
\end{abstract}

\section{INTRODUCTION}

Curcumin, bis (4-hydroxy-3-methoxyphenyl)-1,6-diene3,5-dione, is a hydrophobic polyphenol compound derived from the roots of the Curcuma longa plant. Curcumin is one of the largest components in curcuminoid compounds that are found in the roots of these plants ${ }^{1,2}$. Curcumin has several pharmacological effects including antioxidant, anti-inflammatory, antifungal, antibacterial and anticancer ${ }^{3}$. As an antioxidant compound, curcumin can reduce or prevent various cell damage ${ }^{4}$. The anti-inflammatory activity of curcumin is shown by inhibition of several compounds involved 
in inflammation, such as phospholipase, lipoxygenase, cyclooxygenase ${ }^{5}$. Curcumin also suppresses pro-inflammatory cytokines, TNF- $\alpha$ expression, and release which are mediated through regulation of gamma peroxisome proliferator-activated receptor (PPAR- $\gamma)$. The anti-inflammatory effect of curcumin can be attributed to PPAR- $\gamma$. In that study, there was an increase in mRNA and PPAR- $\gamma$ protein expression after curcumin was given, and the anti-inflammatory effect of curcumin was not seen when given the PPAR- $\gamma$ antagonist ${ }^{6}$.

Many in-vitro studies on curcumin activity are carried out in ovarian cancer-sustainable cells. Inhibition of apoptotic proliferation and stimulation was seen in in-vitro studies on human ovarian cancer cells through increased expression of proapoptosis (bax) genes and decreased anti-apoptotic gene expression (bcl-2) in Ho-8910 sustainable cells and Zeshun Yu et al. in SKOV3 through cell inhibition inhibits the PI3K/Akt signal pathway which plays a role in cell growth, proliferation, and metabolism $^{7,8}$.

Curcumin is a hydrophobic compound that is practically insoluble in water ${ }^{9}$. Curcumin has a low bioavailability. This can be caused by low absorption of curcumin, high metabolism and the rapid elimination of the body. The low bioavailability of curcumin seen in several studies in experimental animals as well as in humans causes the use of curcumin to be limited in vivo. Preliminary studies related to the pharmacokinetics of curcumin carried out by Wahlstrom and Blennow using Sprague Dawley mice, showed that curcumin had poor absorption in the intestine where plasma levels of curcumin were not found after dosing of $1 \mathrm{~g} / \mathrm{kg} \mathrm{BW}^{10}$.

Curcumin has low absorption in the gastrointestinal tract due to the low solubility in water $(0.03 \mu \mathrm{M})$. The presence of a mucus barrier consisting of glycoprotein, water, lipids can block its diffusion from the lumen to the surface of the enterocyte. Mucus can bind to curcumin in a nonspecific way both with protein and fat. The elimination of mucus using NAcCys as a mucolytic carried out by Berginc et al on mice can increase the absorption of curcumin. Although curcumin is lipophilic $(\log \mathrm{P}>3)$, the permeability of curcumin in membranes is very dependent on $\mathrm{pH}$ where permeability increases in an acidic atmosphere ${ }^{11}$.

Curcumin has poor bioavailability. The systemic bioavailability of curcumin is bad due to poor intestinal absorption. Most of the curcumin consumed will be removed with feces, only a small portion is absorbed and widely converted to water-soluble metabolites, glucuronides, and sulfates which are then re-excreted. This situation limits curcumin to reach distant target organs ${ }^{12}$.

Several attempts have been made to increase the absorption of curcumin, one of which is nanoparticles ${ }^{13}$. Drug delivery systems with nanoparticle technology have been used to overcome the bioavailability problems of therapeutic agents. Nanoparticles are very suitable for hydrophobic compounds such as curcumin. Drugs made in the form of nanoparticles generally will quickly diffuse through the tight junction gap to immediately circulate to a specific place or directly to the expected cell target ${ }^{14}$. In the form of curcumin nanoparticles, it is also known to increase cellular uptake, but its distribution to organs is not yet known ${ }^{15}$. Nanoparticles can increase penetration, increase plasma concentration, increase the bioavailability of curcumin, increase cellular permeability, protect curcumin from degradation and metabolism and will be absorbed in specific sites or target targets for desired drugs ${ }^{16}$.

Nanoparticles also influence molecular/drug distribution. This distribution is influenced by the ability of molecules to cross the tissue. Tissues that have gaps in the endothelial wall contribute to the distribution of particles, such as the liver, spleen, bone marrow and tumors. The speed of nanoparticle uptake is based on permeability and retention, also known as the Enhanced Permeability Retention (EPR) phenomenon and in tumor tissue, there is an increase in capillary permeability. Therefore, nanoparticles can increase the distribution of tissues or organs so that they can affect the efficacy and side effects of a drug in the form of nanoparticles. ${ }^{17}$ Nanoparticle curcumin is a drug delivery system that is widely used and is known to increase uptake into cells (cellular uptake) $)^{8}$.

This study was conducted to determine whether the formulation of nanoparticle curcumin by the encapsulation of chitosan using ionic gelation method can increase the absorption of curcumin so that the concentration of curcumin in the liver, kidney and ovarian tissues increases. This study also measured the levels of curcumin in ovarian cancer model rats that given nanoparticle curcumin and compared with unmodified curcumin. Nanoparticle curcumin is expected to be one of the additional therapeutic modalities as nephroprotector, hepatoprotector and in ovarian cancer therefore the survival of patients can increase significantly. 


\section{MATERIALS AND METHODS}

\subsection{Materials}

Curcumin (PT. Plamed Green Science Limited, China, total curcuminoid content, $\geq 95 \%$ ), CMC-Na, curcumin standard (Sigma, Aldrich), sodium tripolyphosphate (Brataco, Indonesia), chitosan (Sigma, Aldrich); glacial acetic acid P; P hydrochloric acid $(\mathrm{HCl})$; dimethyl sulfoxide $\mathrm{P}$ (DMSO); 70\% ethanol P; propylene glycol; tween 80; glycerin; Kolliphor EL (Sigma); potassium dihydrogen phosphate (KH2PO4); sodium chloride $(\mathrm{NaCl})$; aqua destilata; aqua bidestilata; 7,12dimethylbenz [a] anthracene (DMBA), Kalium hydrogen phosphate (K2HPO4), alcohol, betadine, sterile gauze, round cotton, silk thread 3-0, catgut, ketamine, xylazine, $\mathrm{NaCl} 0.9 \%$ (PT. Widatra Bakti), propanolol (as an internal standard), methyl tert-butyl ether / MTBE (Merck), $0.1 \%$ formic acid (Merck), Acetonitrile (Merck), Methanol (Merck).

\subsection{Methods}

\subsubsection{Formulation of curcumin nanoparticles}

The formulation of curcumin nanoparticles was carried out at the Faculty of Pharmacy at the Pancasila University. Chitosan polymer is made in $1 \% \mathrm{~b} / \mathrm{v}$ in glacial acetic acid. 1 gram of powdered curcumin was dissolved in a solvent consisting of propylene glycol, ethanol, DMSO, tween, glycerin, and cremophore. Curcumin and chitosan solutions were mixed using a magnetic stirrer (magnetic stirrer) at a speed of $300 \mathrm{rpm}$ at room temperature. Furthermore, it was dripped with $0.3 \%$ NaTPP in a $300 \mathrm{rpm}$ magnetic stirrer to form nanoparticles.

\subsubsection{Measurement of Curcumin levels in rats,} kidneys and ovaries 3 hours after single oral preparation

This study was an in vivo experimental test in experimental animals (Wistar strain female rats) to determine the levels of curcumin in the liver, kidneys, and ovaries from the administration of chitosan-based curcumin and nanoparticle curcumin. This research was carried out after the Health Research Ethics Committee's obtaining approval from the Faculty of Medicine Universitas Indonesia (approval number: 1188/UN.2 F1/ETIK/2018).

Wistar strain female rats weighing 150 200 grams from the Laboratory of Research and Development of Biomedical and Basic Health Technology, Balitbangkes, Ministry of Health of the Republic of Indonesia. Animals are placed in a room with constant temperature and humidity, adequate lighting, pellet food, and water ad libitum. The animals were divided into 2 treatment groups $(n=5)$ randomly, the curcumin group (female rats given unmodified curcumin with dose $100 \mathrm{mg} / \mathrm{kgBW}$ ) and the curcumin nanoparticles group (female rats given curcumin nanoparticles with dose $100 \mathrm{mg} / \mathrm{kgBW}$ ). Three hours after oral administration, the rats were euthanasia for kidney, liver, and ovarian tissue.

\subsubsection{Measurement of curcumin levels in ovaries} at rats with ovarian cancer models after repeated oral administration for 30 days

An ovarian cancer model rats made by implantation of a thread coated with 7,12dimethylbenz (a) anthracene (DMBA) on the ovary of the rat as a model of animal ${ }^{18}$ for testing curcumin levels in the ovary organs after oral repeated administration for 30 days. Approximately $2 \mathrm{~cm}$ of sterile silk suture 3-0 coated with DMBA $(2 \mathrm{mg})$ implanted in ovarian tissue. The surgery begins with intraperitoneal administration using ketamine and xylazine. Surgery is performed on the retroperitoneal side, and the ovary is cleared of fat tissue. 3-0 silk suture coated with DMBA was implanted in ovarian tissue and the wound was again closed. After the surgical process, the rats are kept fed according to the conditions above. It takes at least 28 weeks from the implantation process to form a tumor period ${ }^{18}$. After 28 weeks, female rats from the Wistar strain who had received DMBA implantation were divided into 2 groups (i) The treatment group received unmodified curcumin $(100 \mathrm{mg} / \mathrm{kg} \mathrm{BW} /$ day) for 30 days (ii) The treatment group received nanoparticle curcumin $(100 \mathrm{mg} / \mathrm{kg}$ BW/day) for 30 days. After administration of the test material for 1 month, the mouse was euthanized for ovarian organs.

\subsubsection{Tissue samples}

Organ/tissue samples (liver, kidney, and ovary) were washed with saline solution and then dried with filter paper and weighed. The ovarian homogenate is made by $100 \mathrm{mg}$ of ovarian tissue in $1 \mathrm{ml}$ of Normal Saline $0.9 \%$ using Ultraturax ${ }^{\circledR}$ homogenizer, then centrifuged at $12,000 \mathrm{rpm}$ for 5 minutes at $-4^{\circ} \mathrm{C}$.

\subsubsection{Validation and Measurement of curcumin levels in organs}

Measuring the level of curcumin in the plasma and ovarian organs was carried out at PT. Farmalab Indoutama, Jakarta, Indonesia 
uses LC-MS / MS (Waters). The analytical method and validation of the LC-MS/MS analysis of determining curcumin levels in biological samples follows European Medicine Agency (EMA) Guideline on bioanalytic method validation ${ }^{19,20}$.

\subsubsection{Sample stability}

Sample stability test was conducted to evaluate the analyte stability in homogenate tissue samples under long-term (30 days) at $-80^{\circ} \mathrm{C}$. The test was performed using three replicates of low QC (3 ng/ml) and high QC (24 ng/ml) sample that are analyzed immediately after preparation and after the applied storage conditions for evaluation. Sample was considered to be stable if the mean value and $\mathrm{CV}$ at the level should be within $\pm 15 \%$ for accuracy and precision ${ }^{20}$.

\subsubsection{Measurement of curcumin levels in liver,} kidney and ovarian homogenates

Measurement of curcumin levels in homogenate using LC-MS/MS instruments. The LC-MS/MS system used was UPLC Waters and tandem mass spectrometry with a positive electrospray ionization source (ESI). Separation of analyte in the sample using a liquid chromatography system with Acquity UPLC ${ }^{\circledR}$
BEH C18 column and mobile phase gradient in the form of $0.1 \%$ and acetonitrile formic acid with a ratio of $72: 28$ with analyte rate of 0.3 $\mathrm{ml} /$ minute and injection volume of $3 \mu \mathrm{L}$. The retention time for curcumin and internal standards is in 2.5 and 1.6 minutes $^{19}$. The mass spectrometric detector parameters were optimized and set as follow: argon desolvation as $350^{\circ} \mathrm{C}$ with a flow rate of $5001 /$ hour and capillary voltage of 3.5 V. During analyses, ESI parameters were performed in positive ion mode and set as follow: parent $\mathrm{m} / \mathrm{z}$ and cone voltage are 369 and $34 \mathrm{~V}$ for curcumin analysis and 260 and $42 \mathrm{~V}$ for IS analyses; daughter $\mathrm{m} / \mathrm{z}$ and collision energy are 177 and $22 \mathrm{~V}$ for curcumin analyses and 183 and $17 \mathrm{~V}$ for IS analyses ${ }^{19}$.

\subsubsection{Standard and internal standard solution preparation}

The standard solution calibration curve is made to the concentrations of $1,2.5,5,10,20$ and $30 \mathrm{ng} / \mathrm{mL}$. Sample quality control (QC) is made in 3 different concentrations, such as 3 $\mathrm{ng} / \mathrm{mL}$ as Low QC, $15 \mathrm{ng} / \mathrm{mL}$ as Medium QC, and $24 \mathrm{ng} / \mathrm{ml}$ as High QC. Standard internal solution (propranolol) is made by dissolving in distilled water so that the concentration of 400 $\mathrm{ng} / \mathrm{ml}$ is obtained ${ }^{21}$.
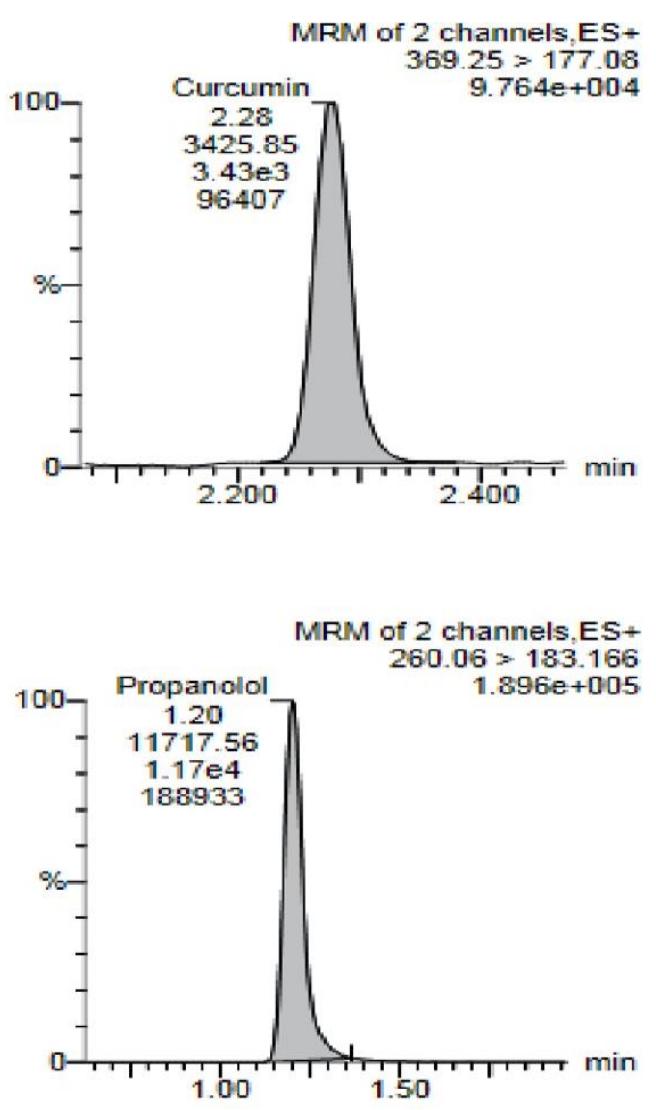

Figure 1. Representative chromatogram UPLC-MS/MS of Curcumin and Internal Standard in rat organ. 


\subsubsection{Sample Preparation}

Two hundred $\mu \mathrm{L}$ of homogeneous samples (liver, kidney, ovary) containing curcumin was added $20 \mu \mathrm{L}$ internal standard and $2 \mathrm{ml}$ MTBE as extraction solution, then vortex for 1 minute and centrifuged at $3000 \mathrm{rpm}$ for 10 minutes. The supernatant was transferred to the test tube and evaporated using an evaporator which was gassed with nitrogen gas at $600 \mathrm{C}$ for 2 minutes. The residue obtained was reconstituted with $100 \mu \mathrm{L}$ of the mobile phase and vortex for 30 seconds. The solution was centrifuged at 12,000 rpm for 5 minutes and ready to use LC-MS/MS.

\subsubsection{Calculation of levels in plasma and homogenates}

The level of curcumin is obtained from the extrapolation ratio between the area of curcumin and the area of propanolol in the sample into the equation of the standard curcumin curve. The area of the analyte twice above the blank area is taken into account in the analysis.

\subsubsection{Statistic analysis}

Data are presented as the mean \pm SE. Each data was tested for the normality of its distribution with Shapiro Wilk and the homogeneity of its variants with the Levene test. The Student's test was used for assessing unequal variance. A 2-tailed value of less than 0.05 was considered significant.

\section{RESULT}

In this study validation method of measuring curcumin levels in homogenate organs included accuracy, precision, and LLOQ (lower limit of quantification). The deviation of the accuracy value of the actual value of organ homogeneity was -7.86 to $-10.65 \%$. In organ homogenates, the coefficient of variation of precision was $3.04 \%-6.89 \%$. In homogenate organs, the lowest level limit that can be measured is $1 \mathrm{ng} /$ $\mathrm{mL}$ and the accuracy value obtained ranges from $5.17 \%-5.76 \%$ and the coefficient of variation is $9.14 \%$. The value received by EMA is no more than $20 \%$ for the value of the deviation of the level and coefficient of variation ${ }^{20}$. With the results of these validations, a method of measuring curcumin levels in homogenate organs can be used. The retention times of curcumin and IS were 2,28 and 1.20 minutes, respectively (Figure 1). The long-term sample stability data were shown in Table 1 . They showed that the analyte was stable until 30 days due to their accuracy and precision in this condition.

Table 1. Accuracy and precision of long term stability in rat organ.

\begin{tabular}{cccc}
\hline Nominal conc. $(\mathbf{n g} / \mathbf{m l})$ & $\begin{array}{c}\text { Measured conc. }(\mathbf{n g} / \mathbf{m l}) \\
(\text { mean } \pm \text { SD) }\end{array}$ & Mean accuracy $(\%)$ & Precision $(\% \mathbf{C V})$ \\
\cline { 3 - 4 } & $2.75 \pm 0.25$ & 91.67 & 2.16 \\
24.00 & $22.53 \pm 0.78$ & 90.16 & 3.76 \\
\hline
\end{tabular}

3.1. Levels of curcumin and nanoparticle curcumin in the liver, kidneys and ovaries of rats

Measuring the levels of curcumin and nanoparticle curcumin on liver homogenates after 3 hours of oral administration showed that nanoparticle curcumin levels were detected to be greater than the levels in the curcumin group. The concentration level of curcumin in the liver, kidney, and ovarian homogenate in the group that received unmodified curcumin were less than the detection limit and the level of curcumin in liver, kidney, and ovarian homogenate in the group receiving nanoparticle curcumin were $1,866.60 \pm 226.01 \mathrm{ng} / \mathrm{g} ; 114.87 \pm 13.36$ $\mathrm{ng} / \mathrm{g}$; and $136.86 \pm 11.15 \mathrm{ng} / \mathrm{g}$ respectively. Levels and ratios can be seen in Table 2 and Figure 2 .

Table 2. Levels of curcumin on liver, kidney and ovaries homogenate.

\begin{tabular}{cccc}
\hline \multirow{2}{*}{ Organ } & \multicolumn{2}{c}{ Measured conc. (ng/g) } & \multirow{2}{*}{ Ratio } \\
\cline { 2 - 3 } & Curcumin (n) & Curcumin nanoparticle (n) & $0: 1,866.6$ \\
Liver & $0.00 \pm 0.00(5)$ & $1,866.60 \pm 226.01(5)$ & $0: 114.8$ \\
Kidney & $0.00 \pm 0.00(5)$ & $114.87 \pm 13.36(5)$ & $0: 136.8$ \\
Ovaries & $0.00 \pm 0.00(5)$ & $136.86 \pm 11.15(5)$ & \\
\hline
\end{tabular}

Description: $n=$ number of subjects detected, data is presented in mean values $\pm S D$

\subsection{Levels of curcumin in ovaries at rats with ovarian cancer models}

Levels of curcumin in homogenate ovaries rats with ovarian cancer after 30 days oral administration of the sample at a dose of $100 \mathrm{mg} / \mathrm{kg}$ showed the level of curcumin in the group that received nanoparticle curcumin detected were greater than the levels in in the group that received unmodified curcumin. This can be seen in Table 3 and Figure 3. 
Table 3. Levels of curcumin in ovarian homogenates cancer rats.

\begin{tabular}{cccc}
\hline \multirow{2}{*}{$\begin{array}{c}\text { Sampling time } \\
(\text { day) }\end{array}$} & \multicolumn{2}{c}{ Measured conc. (ng/g) } & \multirow{2}{*}{ Ratio } \\
\cline { 2 - 3 } & Curcumin (n) & Curcumin nanoparticles (n) & $1: 7.76$ \\
\hline 30 & $2.288 \pm 1.16(5)$ & $17.766 \pm 4.85(5)$ & 10
\end{tabular}

Description: $n=$ number of subjects detected, data is presented in mean values $\pm S D$

\section{DISCUSSION}

Curcumin has been widely used in traditional medicine. Many studies have been conducted to find out the benefits and it was found that curcumin has several pharmacological effects including anti-inflammatory, antioxidant, antiviral, antifungal, antibacterial, immunomodulatory, and anticancer ${ }^{3}$. Curcumin can inhibit tumor growth, angiogenesis and induce apoptosis ${ }^{22,23}$.

In the present study, level of curcumin in the liver, kidney, and ovarian homogenate in the group that received unmodified curcumin after 3 hours were less than the detection limit. The levels of curcumin in organ are found to be very low due to the high metabolism of curcumin in the body. This causes limited use of curcumin in vivo. Curcumin is metabolized into more polar compounds so that it can be excreted from the body. Curcumin undergoes metabolism both phase 1 and phase 2 . In phase 1 , curcumin undergoes a double bond reduction in the structure of heptadione-3,5-dion which is catalyzed by NADPH-dependent curcumin/ dihydrocurcumin reductase to tetrahydrocurcumin and hexahidrocurcumin which are widely formed metabolites, and reduced to small amounts of dihydrocurcumin and hexahidrocurcuminol. The enzymes involved in phase 1 are found in the cytosol of the liver and intestine. Also, another enzyme that plays a role in alcohol dehydrogenase. In phase II metabolism, curcumin and/or its metabolites will be conjugated with monoglukuronida or monosulfate which are catalyzed by the enzyme $\beta$-glucuronidase and sulfatase. The metabolites that are formed include curcumin glucuronide and curcumin sulfate which are found in the urine in the administration of oral curcumin, dihydrocurcumin glucorinda, tetrahydroxycurcumin (THC) glucuronide, hexahidrocurcumin (HHC) glucuronide which is found in bile $\mathrm{e}^{24,25,26}$.

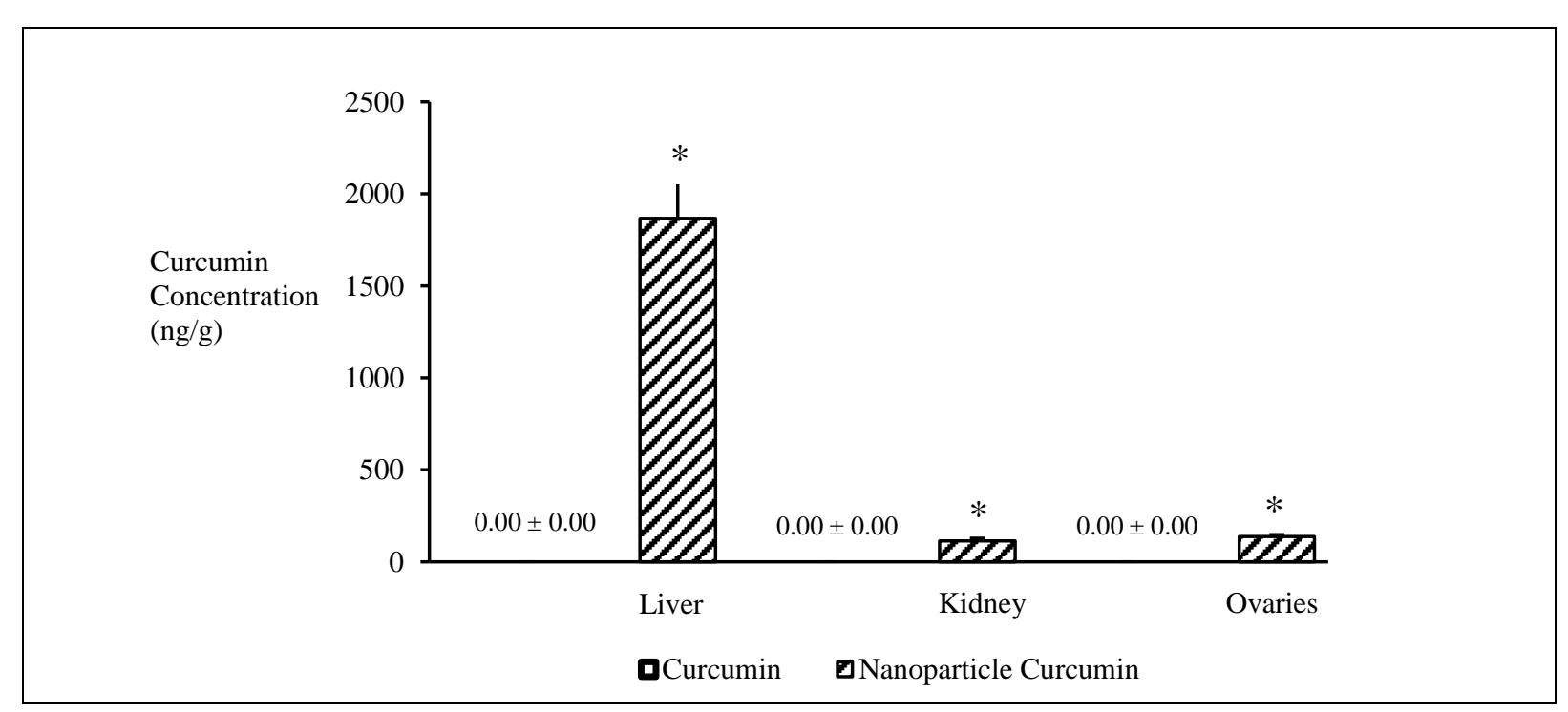

Figure 2. Curcumin level curve in rat liver, kidney and ovaries. The group given curcumin nanoparticles had higher levels of curcumin than the group given curcumin. These results were obtained 3 hours after administration of the test agent dose of $100 \mathrm{mg} / \mathrm{kgBW}$. (*p $<0.05$ VS the curcumin group)

Holder et al. found that most of the curcumin metabolites were found in feces on oral or intraperitoneal administration. Giving labeled deuterium and tritium curcumin intravenously and intraperitoneally in mice showed that curcumin was excreted through bile with the largest metabolites of THC and HHC glucuronide, and metabolite dihydroferulate and ferulic acid in small quantities ${ }^{27}$. In addition, the enzyme UDPglucuronosyltransferase (UGT) also plays a role in metabolizing curcumin ${ }^{25,28}$. The distribution of curcumin in organs is very low. Ravichandran, 2013 
conducted a study on the distribution of curcumin in several organs such as kidneys, liver, lungs, brain, and heart. The levels measured in the liver and kidneys were greater than the other organs with time to reach 90 minutes $^{39}$. Bharat B. Aggarwal, 2013 also reported the results of the distribution of curcumin at a dose of $340 \mathrm{mg} / \mathrm{kg}$ BW after 2 hours is very low ${ }^{40}$. Jigni Mishra, 2017 did not get curcumin levels in the liver and kidneys after administering curcumin orally at a dose of $50 \mathrm{mg} / \mathrm{kg} \mathrm{BW}$ in the $90^{\text {th }}$ minute ${ }^{41}$.

In this study, we found the level of curcumin in liver, kidney, and ovarian homogenate in the group receiving nanoparticle curcumin were $1,866.60 \pm 226.01 \mathrm{ng} / \mathrm{g} ; 114.87 \pm 13.36 \mathrm{ng} / \mathrm{g}$; and $136.86 \pm 11.15 \mathrm{ng} / \mathrm{g}$ respectively. Levels of curcumin in homogenate ovaries rats with ovarian cancer after 30 days oral administration of the sample at a dose of $100 \mathrm{mg} / \mathrm{kgBW}$ showed the level of curcumin in the group that received nanoparticle curcumin detected were greater than the levels in in the group that received unmodified curcumin. Metabolism and drug elimination can also be affected by particle size. Large drugs/molecules are metabolized faster because the drug will be distributed to the liver in large numbers and recognized by macrophages that are widely found in liver tissue which will then be metabolized and eliminated from the body. This is known as the reticuloendothelial system (reticuloendothelial system / RES). Therefore, the nanoparticle formulation was developed to avoid RES by minimizing its bond to the protein so that it would increase the circulation time of the drug. Increased drug circulation time can be seen from the clearance $(\mathrm{Cl})$ and half-life $(\mathrm{t} 1 / 2)$. The smaller the clearance and the greater the half-life of the meal, the circulation of the drug will be longer and so the amount of drug in the blood is large $(\mathrm{AUC})^{17}$. Because nanoparticles can influence the process of absorption, distribution, metabolism, and elimination of drugs, the nanoparticles can influence the pharmacokinetic profile of the drug. Drugs that use a lot of this technology are generally drugs that have low solubility in water and/or low oral bioavailability ${ }^{14,29}$.

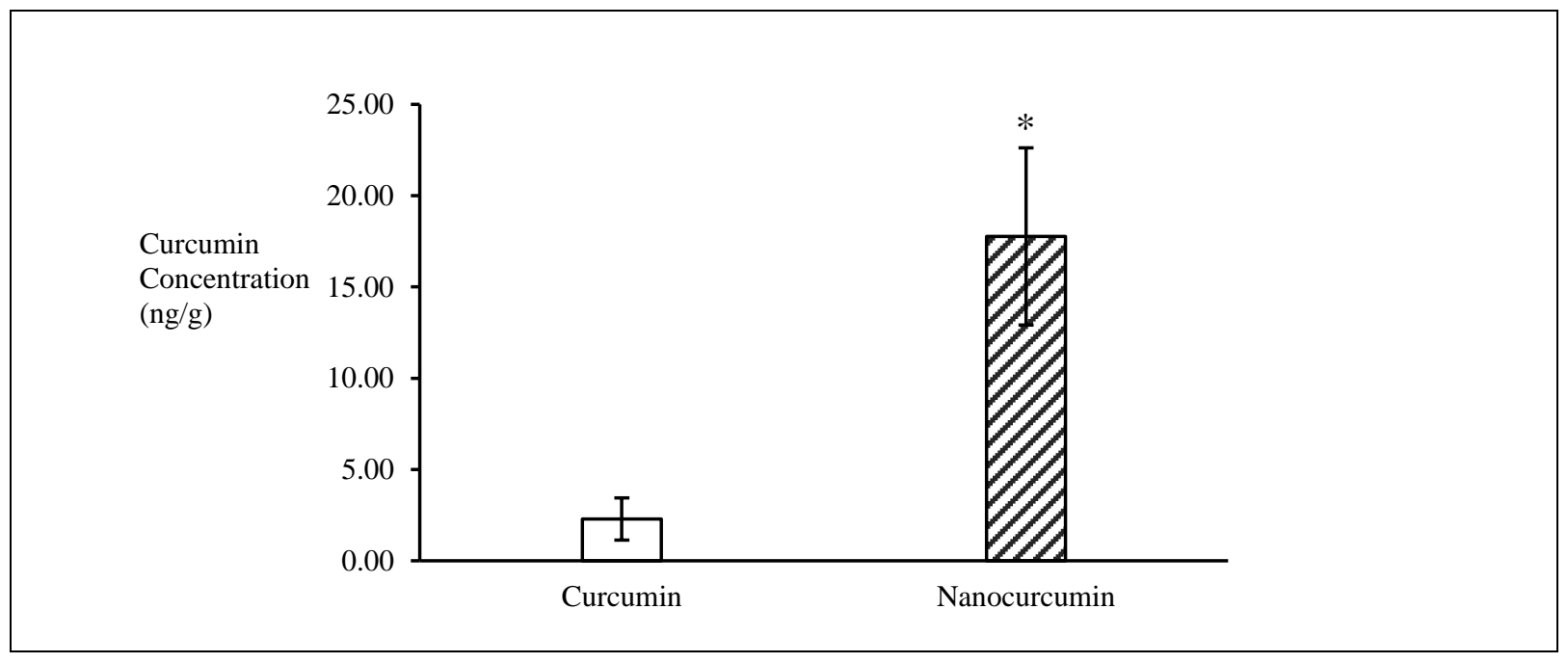

Figure 3. Curcumin level curve in ovarian cancer rats. The group given curcumin nanoparticles had higher levels of curcumin than the group given curcumin. This result was obtained 30 days after administration of the test agent dose of $100 \mathrm{mg} / \mathrm{kgBW}$. ( ${ }^{*} p<0.05$ VS the curcumin group)

Particle size also affects the transport process across the membrane and impacts the absorption process. Nanoscale particles/molecules $(1-1,000 \mathrm{~nm})$, especially with a range of 1-100 nm, can be transported through the mechanism of paracellular uptake, transcellular uptake by enterocytes, and transcellular uptake by $\mathrm{M}$ cells. Paracellular transport is transport through the gap between epithelial cells with disturbing the tight junction reversibly or through aquaporin in the gastrointestinal tract. Nanoparticles less than 20 $\mathrm{nm}$ can enter the circulatory system by reversing the tight junction. Nanoparticles with the use of certain polymers can also disturb the tight junction so that it increases paracellular transport ${ }^{30}$. On transcellular nanoparticles (transcytosis) uptake, there are passive diffusion or involving receptors on cell surfaces that recognize nanoparticles specifically. The mechanism applies to transcellular uptake by enterocytes and $\mathrm{M}$ cells. $\mathrm{M}$ cells are more permeable than enterocytes so they can be targeted at micro delivery systems or nanoparticles ${ }^{31}$. 
In this study, curcumin nanoparticles were made by ionic gelation method. In this method, cross-linking or beads occur, which is a bond formed between the polymers and the active site of the hydrophilic part which binds to the cross-linking agent to form structured and modified polymer strands.

The selection of crosslinking agents needs to be considered regarding stability, solubility, and $\mathrm{pH}$ when reacted together with the polymer to be used at optimum conditions so that it is possible to form stable synthesis results. Chitosan is an ideal polymer, has biodegradable properties and is biocompatible with other medicinal or excipient materials, such as nontoxic, inert and does not cause immune reactions to the body. Besides, it has swellable, edible and adhesive properties by forming a gel when it comes in contact with mucous fluid through its ionic bond. Chitosan can be applied for drug delivery both in microencapsulation systems, microspheres and in the manufacture of nanoparticle techniques. For this reason, this polymer is widely used as a mucoadhesive polymer $^{32,33,34,35}$. As a cross-linker, STPP was used in this study. STPP is inert, non-allergic, noncarcinogenic, biodegradable and biocompatible with the body. In general, STPP is used as a crosslinking agent or often referred to as a crosslinking agent for the synthesis of microparticles and nanoparticles with the polymer it reacts with. Variations in the use of concentration and a large amount of material used can affect the results of the formation of microparticles or nanoparticles. Therefore, optimization needs to be done first to require the desired synthesis ${ }^{36,37}$. Chitosan is a positively charged (cationic) polymer reacted with a negatively charged (anionic) crosslinking agent so that the binding mechanism occurs ionically to form stable ions or molecules in the strands of the polymer chain. Tripolyphosphate (-PO3H-) ion from sodium tripolyphosphate compound through its polyanion charge will interact with quaternary amine groups $(-\mathrm{NH} 3+)$ from chitosan polymers through polycation loads forming stable ionic bonds $s^{36,37,38}$. With the nanoparticle formulation, curcumin can reach the target organ compared to unmodified curcumin. The encapsulation of curcumin with chitosan polymer protects curcumin from stage 1 and 2 RES and metabolism systems.

With the modification of particle size and the use of polymers can increase the distribution of curcumin in the organ and can reach the target organ. The submicron-sized particles are useful for drug delivery models with controlled-release targets as carriers that mediate the drug model so that the drug directly works to the target ${ }^{14,29}$. The form of curcumin nanoparticles in this study can increase the levels of curcumin in the liver, kidneys, and ovaries after being given orally in rats. In ovarian cancer model rats, there were also differences in the group that received nanoparticle curcumin and the group that received unmodified curcumin on repeated 30-day administration. This can provide information on curcumin formulations so that they can be developed and utilized in vivo and provide optimal pharmacological effects on the liver as hepatoprotection, kidney organs as renoprotection and use in ovarian cancer.

\section{CONCLUSION}

There are significant differences levels of curcumin from unmodified curcumin with curcumin nanoparticles in liver, kidney ovarian. The levels of curcumin in the form of nanoparticles are higher than unmodified curcumin in these organs, so the formulation of curcumin nanoparticles is a potential therapeutic agent such as hepatoprotection, organ kidney as renoprotection and use in ovarian cancer.

\section{ACKNOWLEDGEMENT}

We gratefully acknowledge the financial support of the Ministry of Research Technology and Higher Education, National Ministry of Republic Indonesia for research grant of Penelitian Disertasi Doktor 2019.

\section{Conflict of interest}

The authors declare no conflict of interest.

\section{Funding}

This study has funding from the Ministry of Research Technology and Higher Education, National Ministry of Republic Indonesia for research grant of Penelitian Disertasi Doktor 2019.

\section{Ethical approval}

Ethical approval from the Faculty of Medicine Universitas Indonesia (approval number: 1188/UN.2 F1/ETIK/2018).

\section{Article info:}

Received December 13, 2019

Received in revised form March 3, 2020

Accepted April 24, 2020

\section{REFERENCES}

1. Kurita T, Makino Y. Novel curcumin oral delivery systems. Anticancer Res. 2013;33(7):2807-21. 
2. Siviero A, Gallo E, Maggini V, et al. Curcumin, a golden spice with a low bioavailability. J Herb Med. 2015;5(2):57-70.

3. Maheshwari RK, Singh AK, Gaddipati J, Srimal RC. Multiple biological activities of curcumin: a short review. Life Sci. 2006;78(18):2081-87.

4. Babu D, Gurumurthy P, Borra SK, Cherian K. Antioxidant and free radical scavenging activity of triphala determined by using different in vitro models. J. Med. Plants Res. 2013;7(39):2898-905.

5. Jurenka JS. Anti-inflammatory properties of curcumin, a major constituent of Curcuma longa: a review of preclinical and clinical research. Alternative medicine review. 2009;14(2).

6. Siddiqui AM, Cui X, Wu R, et al. The antiinflammatory effect of curcumin in an experimental model of sepsis is mediated by up-regulation of peroxisome proliferator-activated receptor-gamma. Crit Care Med. 2006;34(7):1874-82.

7. Shi M, Cai Q, Yao L, Mao Y, Ming Y, Ouyang G. Antiproliferation and apoptosis induced by curcumin in human ovarian cancer cells. Cell Biol Int. 2006;30(3):221-6.

8. Stewart B, Wild CP. World cancer report 2014. Health. 2017.

9. Heger M, van Golen RF, Broekgaarden M, Michel MC. The molecular basis for the pharmacokinetics and pharmacodynamics of curcumin and its metabolites in relation to cancer. Pharmacol Rev. 2014;66(1):222-307.

10. Wahlström B, Blennow G. A study on the fate of curcumin in the rat. Basic \& Clinical Pharmacology \& Toxicology. 1978;43(2):86-92.

11. Berginc K, Trontelj J, Basnet NS, Kristl A. Physiological barriers to the oral delivery of curcumin. Die Pharmazie-An International Journal of Pharmaceutical Sciences. 2012;67(6):518-24.

12. Avachat A, Ahire V. Characterization and evaluation of spray dried co-processed excipients and their application in solid dosage forms. Indian J Pharm Sci. 2007;69(1):85.

13. Ravindranath V, Chandrasekhara N. Absorption and tissue distribution of curcumin in rats. Toxicology. 1980;16(3):259-65.

14. Mohanraj V, Chen Y. Nanoparticles-a review. Trop J Pharm Res. 2006;5(1):561-73.

15. Bisht S, Feldmann G, Soni S, et al. Polymeric nanoparticle-encapsulated curcumin (" nanocurcumin"): a novel strategy for human cancer therapy. J nanobiotechnology. 2007;5(1):3.

16. Ghalandarlaki N, Alizadeh AM, Ashkani-Esfahani S. Nanotechnology-applied curcumin for different diseases therapy. Biomed Res Int. 2014;2014:394264.

17. Li S-D, Huang L. Pharmacokinetics and biodistribution of nanoparticles. Mol Pharm. 2008;5(4):496-504.

18. Sandhiutami D, Made N, Arozal W, et al. Induction of Epithelial Ovarian Cancer by Implantation of 7, 12dimethylbenz (a) athracene (DMBA) Coated Silk in Rats. Journal of Young Pharmacists. 2019;11(1).

19. Ramadanty WT, Arozal W, Louisa M, Soetikno V, Purbadi S, Priyanto P. Efficient validated method of UPLC-MS/MS to determine curcumin in rat plasma and ovarium. Journal of Applied Pharmaceutical Science. 2019;9(01):058-65.

20. Smith G. European Medicines Agency guideline on bioanalytical method validation: what more is there to say? Bioanalysis. 2012;4(8):865-8.
21. Arozal W, Ramadanty WT, Louisa M, et al. Pharmacokinetic Profile of Curcumin and Nanocurcumin in Plasma, Ovary, and Other Tissues. Drug research. 2019.

22. Lin YG, Kunnumakkara AB, Nair A, et al. Curcumin inhibits tumor growth and angiogenesis in ovarian carcinoma by targeting the nuclear factor-kappaB pathway. Clin Cancer Res. 2007;13(11):3423-30.

23. Choudhuri T, Pal S, Das T, Sa G. Curcumin selectively induces apoptosis in deregulated cyclin D1-expressed cells at G2 phase of cell cycle in a p53-dependent manner. J Biol Chem. 2005;280(20):20059-68.

24. Pan M-H, Huang T-M, Lin J-K. Biotransformation of curcumin through reduction and glucuronidation in mice. Drug Metab Dispos. 1999;27(4):486-94.

25. Liu W, Zhai Y, Heng X, et al. Oral bioavailability of curcumin: problems and advancements. J Drug Target. 2016;24(8):694-702.

26. Hoehle SI, Pfeiffer E, Sólyom AM, Metzler M. Metabolism of curcuminoids in tissue slices and subcellular fractions from rat liver. J Agric Food Chem. 2006;54(3):756-64.

27. Holder GM, Plummer JL, Ryan AJ. The metabolism and excretion of curcumin (1, 7-bis-(4-hydroxy-3methoxyphenyl)-1, 6-heptadiene-3, 5-dione) in the rat. Xenobiotica. 1978;8(12):761-8.

28. Shoba G, Joy D, Josep T, Rajendran MMR, Srinivas P. Influence of piperine on the pharmacokinetics of curcumin in animals and human volunteers. Planta medica. 1998;64:353-6.

29. Ranjit K, Baquee AA. Nanoparticle: An overview of preparation, characterization and application. Int Res J Pharm. 2013;4(4):47-57.

30. Li Z, Jiang H, Xu C, Gu L. A review: Using nanoparticles to enhance absorption and bioavailability of phenolic phytochemicals. Food Hydrocolloids. 2015;43:153-64.

31. Acosta E. Bioavailability of nanoparticles in nutrient and nutraceutical delivery. Current Opinion in Colloid \& Interface Science. 2009;14(1):3-15.

32. Gavhane Y, Gurav A, Yadav A. Chitosan and its applications: a review of literature. Int J Biomed Pharm Sci. 2013;4:312-31.

33. Bernkop-Schnurch A, Dunnhaupt S. Chitosan-based drug delivery systems. Eur J Pharm Biopharm. 2012;81(3):463-9.

34. Qi L, Xu Z, Jiang X, Hu C, Zou X. Preparation and antibacterial activity of chitosan nanoparticles. Carbohydr Res. 2004;339(16):2693-700.

35. Rowe RC, Sheskey PJ, Owen SC. Handbook of pharmaceutical excipients. Vol 6: Pharmaceutical press London. 2006.

36. Bhumkar DR, Pokharkar VB. Studies on effect of $\mathrm{pH}$ on cross-linking of chitosan with sodium tripolyphosphate: a technical note. Aaps Pharmscitech. 2006;7(2):e138-E143.

37. Chuah LH, Billa N, Roberts CJ, Burley JC, Manickam $\mathrm{S}$. Curcumin-containing chitosan nanoparticles as a potential mucoadhesive delivery system to the colon. Pharm Dev Technol. 2013;18(3):591-9.

38. Liu H, Gao C. Preparation and properties of ionically cross-linked chitosan nanoparticles. Polym Adv Technol. 2009;20(7):613-9.

39. Ravichandran R. Pharmacokinetic Study of Nanoparticulate Curcumin: Oral Formulation for Enhanced Bioavailability. J Biomater Nanobiotechnol. 2013;04(03):291-9.

40. Anand P, Kunnumakkara AB, Newman RA, Aggarwal BB. Bioavailability of curcumin: problems and promises. Mol Pharm. 2007;4(6):807-18.

41. Mishra J, Tripathi A, Misra K, SKS S. HPTLC: A Tool for Determination of Curcumin in Mammalian Samples. 